\title{
Development of Telescopic Glasses Optical System Based on Polymer Lens*
}

\author{
Alisa Ekimenkova ${ }^{[0000-0001-5847-7918]}$, Anna Voznesenskaya ${ }^{[0000-0002-4074-4341]}$ \\ ITMO University, 197101, Russia, St. Petersburg, Kronverksky av., 49 \\ asekimenkova@itmo.ru, voznesenskaya@itmo.ru
}

\begin{abstract}
Polymeric materials are actively used to upgrade existing optical devices in order to improve their physical and optical properties. High-tech and relatively cheap polymer optics is a means of solving technical problems related to reduction of assembly labor intensity, improvement of design and reliability of various optical systems. Currently, ophthalmology is the most advanced area for polymer technology development. The defining trend of improving spectacle optics is gradual replacement of lenses made of silicate glass with lenses made of polymer materials, the undoubted advantages of which are almost twice lower density and significant impact resistance. This work is devoted to the development of an optical system of telescopic glasses of small multiplicity, made by the scheme Galileo using modern optical polymers. The device is designed to improve the performance of the eye and can be used for medical operations. The calculation of the presented optical system is carried out by the Zemax program. The resulting optical system is characterized by high image quality, light weight and compactness.
\end{abstract}

Keywords: Optical Polymers, Medical Optics, Telescopic Glasses, Optimization, Aspherical Lenses.

\section{$1 \quad$ Introduction}

In order to improve the eye performance, telescopic glasses with relatively small magnification are used (Fig.1). Such systems have found wide application in medicine, for manufacture of microelectronic schemes and jewels. The special requirement at development of glasses is elimination of necessity for additional accommodation of eyes at transition from observation with glasses and without them. This criterion is achieved due to the location of the object and image in one plane [1-2]. Telescopic glasses guarantee high image clarity without distortion and excessive strain on the eyes, in view of manufacturing strictly in accordance with the individual characteristics of the operator. Image transmission quality is achieved by using premium optics.

Copyright (C) 2020 for this paper by its authors. Use permitted under Creative Commons License Attribution 4.0 International (CC BY 4.0).

* Publication financially supported by RFBR grant №20-01-00547 


\section{A. Ekimenkova, A. Voznesenskaya}

However, traditional glass lenses have a considerable mass, which is a serious disadvantage when glasses are worn for a long time. Therefore, when calculating the optical system, it is necessary to ensure low weight and small size for efficient operation [3].

To reduce the mass and dimensional characteristics, the calculation of telescopic glasses optical system based on polymer lenses is proposed. Modern optical polymers have high transparency and refractive power comparable to that of crown glasses. The specific gravity of plastic is almost half that of glass, which allows the polymer lenses to be much lighter. Currently, polymeric materials have many advantages over mineral glass: low weight, injury safety, high impact resistance and low cost. Besides, today the technologies of production and processing of optical polymers enable to create complex surfaces (diffraction, aspherical, "freeform"), providing compensation of aberrations and transformation of the beam shape [4].

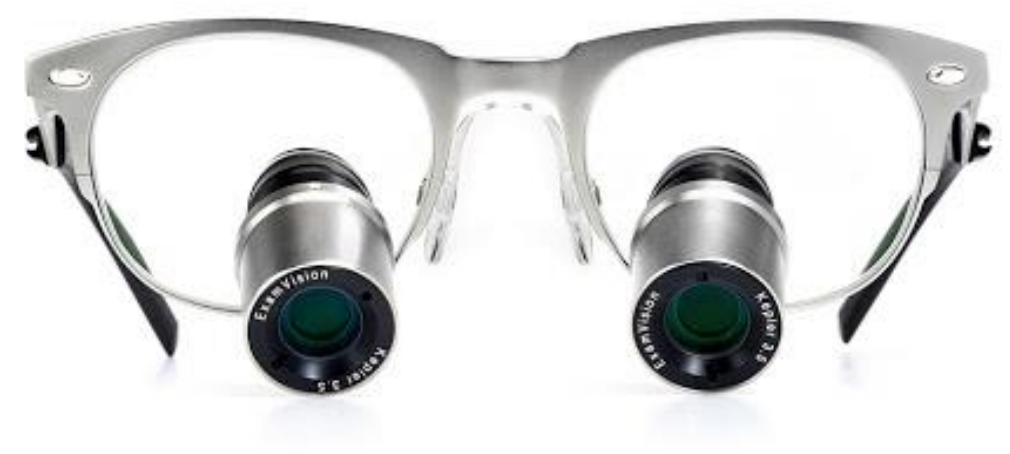

Fig. 1. Telescopic glasses

\section{Ophthalmologic optical polymers}

Ophthalmology is the most common field of application of polymer optics as a means of vision correction and eye protection. The main task of eyeglass optics is to ensure completely natural vision for their wearer. The materials used in the manufacture of corrective lenses must comply with a number of requirements [5]:

- high indexes of refraction and dispersion;

- low reflection and light scattering coefficients for the visible range;

- low transmittance of ultraviolet and infrared radiation;

- small density;

- high hardness; 
- chemical resistance to humid atmospheres;

- low internal voltage;

- easy to handle.

It should be noted that some of these requirements contradict each other and the material with the highest values for all these parameters has not yet been developed.

The fundamental characteristic of glasses is the refractive index $n$ of material, as the thickness of the lenses directly depends on this value. The greater the refractive index, the finer optics can be manufactured. In addition, the value $\mathrm{n}$ also affects the optical power of the lens.

The optical properties of polymer materials for glasses lenses are commensurate with those of traditional glasses. However, the level of light dispersion of polymers is higher and can be manifested by coloring the contour of the object when viewed through the peripheral areas. Nevertheless, as a rule, this defect is not fundamental for most eyeglass wearers. In order to improve functional and operational characteristics of polymer lenses, special coatings are used: to increase wear resistance of polymer material, as a protection, etc. The polymeric materials are used for spherical and aspherical lenses, astigmatic and astigmatic lenses, monofocal lenses, bifocal lenses and lenses of various diameters $(60-75 \mathrm{~mm})$, which can be used for frames of any size [6]. In recent years, there has been a rapid development in the field of high molecular chemical compounds, which has led to the development of optical polymer materials with a refractive index above 1.7. At the same time, the increase of refractive index does not indicate the growth of material density. Today, mineral lenses have the highest refractive index of 1.90, while polymer lenses have a refractive index of 1.74. Organic materials with such refractive index are produced by the Japanese company Mitsui Chemicals [7]. The line of optical polymers of this company $\mathrm{MR}^{\mathrm{TM}}$ is intended for manufacturing of ophthalmic lenses. Due to its unique physical properties and characteristics, it allows creating thin and aesthetic eyeglass lenses, even taking into account the high optical power of components.

Table 1. Optical and mechanical properties of polymer materials

\begin{tabular}{|c|c|c|c|c|c|c|c|}
\hline Material & PMMA & Polyester & PS & PC & $\begin{array}{c}\text { COC, } \\
\text { COP }\end{array}$ & MR-174 & K8 \\
\hline $\begin{array}{c}\text { Refractive index } \\
(\lambda=633 \text { nm) }\end{array}$ & 1,491 & 1,607 & 1,590 & 1,585 & 1,533 & 1,743 & 1,516 \\
\hline Abbe number & 57 & 27 & 31 & 30 & 58 & 32 & 64 \\
\hline $\begin{array}{c}\text { Birefringence, } \\
\text { (on a scale of 1 to } \\
10 \text { ) }\end{array}$ & 4 & 2 & 10 & 7 & 2 & 2 & 1 \\
\hline Transmission, \% & 96 & 94 & 90 & 89 & 92 & 97 & 92 \\
\hline $\begin{array}{c}\text { Density, g/cm }{ }^{3} \\
\text { Maximum operat- } \\
\text { ing temperature, } \\
{ }^{\circ} \mathrm{C}\end{array}$ & 1,8 & 1,22 & 1,05 & 1,25 & 0,95 & 1,38 & 2,51 \\
\hline $\begin{array}{c}\text { Water absorption, } \\
\%\end{array}$ & 0,3 & 0,15 & 0,1 & 0,2 & $<0,01$ & 0,1 & $>400$ \\
\hline $\begin{array}{c}\text { Thermal expan- } \\
\text { sion coefficient, } \\
1^{-4} /{ }^{\circ} \mathrm{C}\end{array}$ & 60 & 72 & 50 & 68 & 60 & 61 & 7,1 \\
\hline
\end{tabular}


Table 1 shows the optical and mechanical properties of the most commonly used polymer materials: polymethylmethacrylate (PMMA), polyester, polystyrene (PS), cycloolefin (co)polymers (COC \& COP), MR-174 and K8 glass [8]. It should be noted that thermal properties of polymers unfavorably differ from glass characteristics, however, plastic density is almost 1.5 times lower, and optical properties of materials are comparable and not inferior to each other.

\section{Telescope glasses calculation}

Optical system of telescopic glasses is arranged according to Galileo's scheme that does not require wrapping elements (Fig. 2).

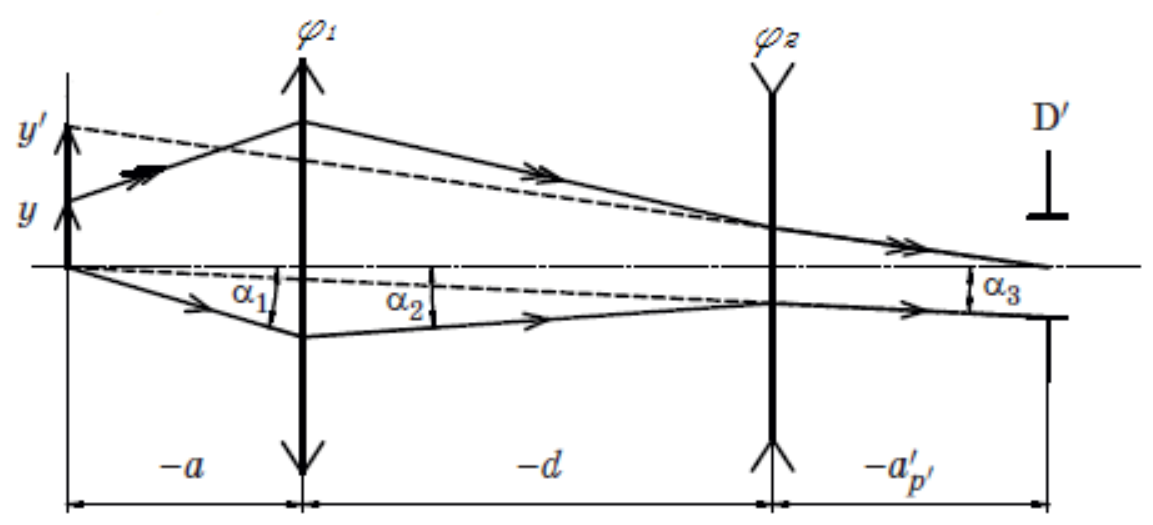

Fig. 2. Principal optical circuit in thin components

The calculation principle for optical systems is based on the method of automatic aberration correction. Initially, the system dimensional calculation is performed and optimization parameters are formed. Then tracing rays in the initial scheme is realized and, if necessary, optimization parameter limits are changed for the purpose of reception for the best quality of the image and observance of design requirements. Table 2 shows the original characteristics of the optical system, which were determined based on the design features. The magnification $\beta$ of similar systems is in the $1.5-3^{x}$, the distance from the main plane of the first component to the plane of objects and images $a$ usually take from 300 to $400 \mathrm{~mm}$. The distance between the main planes of the components $d$ is determined for structural reasons. As this parameter increases, the relative diameters of the lenses are reduced, making it easier to correct aberrations. However, as $d$ rises, the total system size also becomes larger. The focal distances of $f_{1}^{\prime}$ and $f_{2}^{\prime}$ components are determined using the basic formulas of geometric optics [9]. 
Table 2. Primary characteristics of the optical system

\begin{tabular}{|c|c|c|c|c|}
\hline$\beta,^{\times}$ & $a, \mathrm{~mm}$ & $d, \mathrm{~mm}$ & $f^{\prime}{ }_{1}, \mathrm{~mm}$ & $f^{\prime}{ }^{\prime}, \mathrm{mm}$ \\
\hline 3 & 350 & 30 & 41,45 & -16.29 \\
\hline
\end{tabular}

The original glasses system includes positive and negative elements. To minimize chromatic aberrations, optical materials should be selected so that the dispersion coefficients are varied as much as possible. In addition, the Abbe value of the positive component should be higher than that of the negative component [10-11].

During the analysis of modern optical polymer materials and their optical and mechanical properties, the most beneficial components were determined. The final optical system has the following parameters: the first component is a pair of positive lenses made of E48R polymer $\left(n_{\mathrm{e}}=1,531, v_{\mathrm{e}}=56\right)$ of Zeonex commercial brand [12]. This material is a cycloolefin polymer and provides high optical performance. The second component is a negative lens made of specialized ophthalmologic material MR-174 $\left(n_{\mathrm{e}}=1,743, v_{\mathrm{e}}=32\right)$ [7]. Table 3 shows the design parameters of the optical system. Figure 3 illustrates the optical scheme of polymer telescopic glasses.

Table 3. Optical system design parameters

\begin{tabular}{|c|c|c|c|c|c|}
\hline $\begin{array}{c}\text { Surf. } \\
\text { № }\end{array}$ & $\begin{array}{l}\text { Curvature } \\
\text { radius, } \mathrm{mm}\end{array}$ & $\begin{array}{l}\text { Axial distance, } \\
\mathrm{mm}\end{array}$ & Material & $\begin{array}{l}\text { Refractive } \\
\text { index }\end{array}$ & $\mathrm{e}^{2}$ \\
\hline 1 & 39,610 & 2,545 & E48R & 1,531 & \\
\hline 2 & 85,126 & 0,089 & AIR & 1 & \\
\hline 3 & 28,088 & 4,678 & E48R & 1,531 & \\
\hline 4 & 373,926 & 14,633 & AIR & 1 & \\
\hline 5 & $-62,670$ & 3,566 & MR-174 & 1,743 & $-10,416$ \\
\hline 6 & 25,949 & & & & 1,030 \\
\hline \multicolumn{6}{|c|}{$\begin{array}{c}2 \omega^{\prime}=7^{\circ} \\
f^{\prime}{ }_{1}=40,628 \mathrm{~mm} \\
f^{\prime}{ }_{2}=-24,102 \mathrm{~mm}\end{array}$} \\
\hline
\end{tabular}

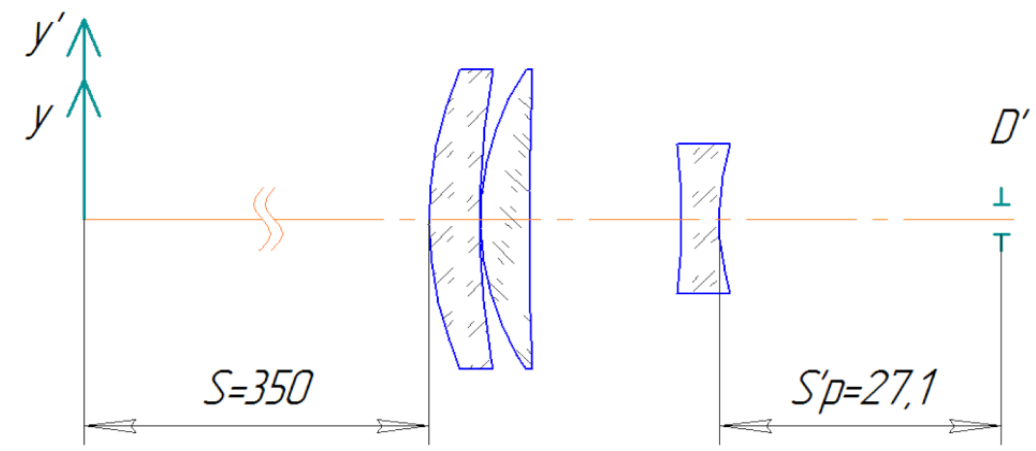

Fig. 3. Optical circuit of polymer telescopic glasses 
Optimization of the optical system has allowed correction of monochromatic aberrations (spherical, coma, image curvature, distortion and astigmatism). Due to the small aperture of the optical system $(A=0,01)$ the residual monochromatic axial aberrations are insignificant, image quality is determined by the size of the diffraction circle (Fig. 4).

OBJ: $0.00 \mathrm{~mm}$

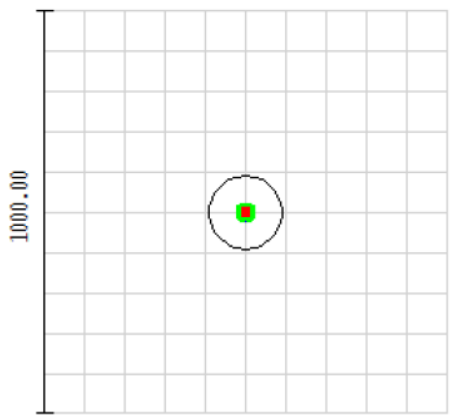

IMA: $-0.000 \mathrm{~mm}$
OBJ: $20.00 \mathrm{~mm}$

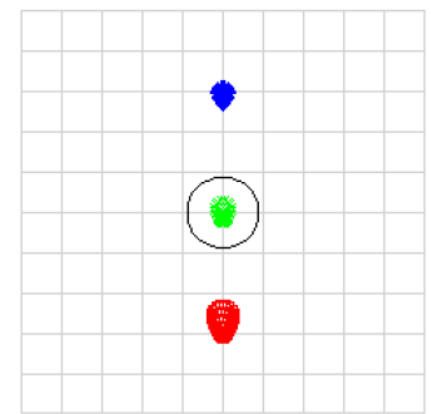

IMA: $38.186 \mathrm{~mm}$

Fig. 4. Spot diagram of scattering

\section{Conclusion}

The resulting optical system has a high image quality, with the mass of polymer glasses less than $50 \%$ of weight of glass analogues. The configuration includes lenses made of modern optical polymers with high index of refraction and dispersion. The technique of manufacturing lenses from optical plastics allows you to make surfaces of complex shape, providing high quality components and low cost.

\section{References}

1. Urmacher L.S., Eisenstat L.I.: Ophthalmological devices. Medicine, Moscow (1988)

2. Slyusarev G.G.: Calculation of the optical systems. Mashinostroenie, Leningrad (1975)

3. Zakaznov N.P., Kiryushin S.I., Kuzichev V.I. Theory of Optical Systems. Mashinostroenie, Moscow (1992)

4. Voznesenskaya A.O, Andreev L.N., Ekimenkova A.S.: Development of surgical binoculars on the basis of polymeric lenses. In: SPIE Optical Engineering + Applications 2017, vol. 10375, p.p. 1037514-1-1037514-6. San Diego, California (2017)

5. Urmacher L.S., Eisenstat L.I.: Optical means of vision correction. Medicine, Moscow (1990)

6. Serova V.N.: Polymeric optical materials. Scientific bases and technologies, SaintPetersburg (2011) 
Development of Telescopic Glasses Optical System Based on Polymer Lens 7

7. Mitsui Chemicals Inc. Homepage, https://jp.mitsuichemicals.com. Last accesed 10 July 2020

8. Beich W.S.: Plastic Optics: Specifying Injection-Molded Polymer Optics Homepage, https://www.photonics.com/Articles/Plastic_Optics_Specifying_Injection-Molded/a25487. Last accessed 21 June 2020

9. Rusinov M.M.: Composition of optical systems. Mashinostroenie, Leningrad (1989)

10. Andreev L.N.: Applied theory of aberrations textbook. ITMO, Saint-Petersburg (2002)

11. Churilovsky V.N.: Theory of Chromatism and Aberrations of the 3rd Order. Mashinostroenie, Leningrad (1966)

12. Zeon Homepage, https://www.zeonex.com. Last accessed 11 July 2020 